\section{Diagnosis of Huntington's chorea}

SIR - There has been a good deal of publicity in the past few weeks over whether or not the predictive test for Huntington's chorea $(\mathrm{HC})$ should be made clinically available. The argument so far seems to have been between James F. Gusella and his colleagues in the United States and the Medical Genetic Unit at Oxford (see Nature 320, 21; 1986).

Dr Gusella's reasons for withholding the test from clinical use appear to be threefold: first, there is still a slight risk of heterogeneity; second, the error rate is higher than at first supposed, and has gone up from 5 per cent to a possible 10 per cent or even 15 per cent in some cases; third, we have as yet no idea of the effects of this test on people, and careful researching of counselling methods needs to be done in controlled situations before it becomes generally available.

It is not within a lay organization's brief to comment on scientific aspects, except to say that we understand that enough evidence has now been gained to make heterogeneity unlikely, and it could, anyway, never be entirely ruled out. A test that was 100 per cent reliable would seem to be preferable, but many of those who are currently at a 50 per cent risk of carrying the $\mathrm{HC}$ gene would rather live with a 10 per cent uncertainty about their future than the situation they are in now. On an exclusion test in pregnancy, we are told that the error rate is likely to be considerably less. The third point regarding counselling seems to be the critical one. People at risk to Huntington's chorea are no different from the rest of the population, except for their anxiety about inheriting HC. Most of them are quite capable of making up their own minds as to whether or not the error rate is acceptable for them, and whether or not they really want to have this test either on themselves or on a fetus. Full and skilled counselling is obviously vital, to make sure both that the facts are understood and that people have considered the repercussions of such a test if it were either negative or positive. Many will need continuing support and help afterwards, as will their families. Members of the medical and allied professions must be concerned about conse quences and mistakes, but by being overprotective they are denying some people the right to take responsibility for their own decisions and lives.

On behalf of this association I would therefore like to state that contact with a large number of people at risk has shown that there is a diversity of opinion within this group, but a significant number would want to take the predictive test even in its present form (on a recent survey, 65 per cent of those already attending a genetic clinic), and would therefore support the release of the test for clinical use providing that any unit administering the test was able to offer extensive pre- and post-test counselling both in the clinic and in the community.

\section{Association to combat \\ Huntington's Chorea, \\ 108 Battersea High Street, \\ London SWII $3 \mathrm{HP}, \mathrm{UK}$}

SIR - As a lay person intimately involved with Huntington's chorea (affected husband, daughter, and three other children at risk) I can only applaud James F. Gusella and those at Massachusetts General Hospital who are so wise and sensitive to the many problems associated with the administration of the predictive test for Huntington's chorea. The test has never been given. No one knows how the results will affect individuals and their families. Until the pilot programme is initiated, concluded and evaluated, the moral and ethical issues, for the greater good, will not be known.

It has taken more than 100 years to come this far. To release the probe for clinical use before the initial pilot programme findings have been reviewed may be an error. Another year to prove that the test is in the best interest of all concerned does not seem unreasonable.

Again, I thank Dr Gusella and his colleagues for looking beyond the slides and test tubes to the individuals this test will ultimately effect.

NATALiE Frank

10 Louder's Lane,

Jamaica Plain, Massachusetts 02130, USA

\section{In defence of curiosity}

SIR-In his comment' on the exchange of letters between Gusella and Watt et al. ${ }^{2}$, John Maddox, while not denying the principle that discoveries are common property, puts unjustified restrictions on the application of this principle by presupposing a researcher's right "to demand a full account of the purposes for which the material is required" and by restricting acceptable purposes: "Mere curiosity is an insufficient basis for a request".

Two important points need to be made: first, discoveries, especially in the biological sciences, are frequently coincident with materials. Thus for researchers without access to the materials, the discoveries are sterile and worthless. Secondly, not only has curiosity been, at least historically, the impetus for the scientific process but it also continues to provide, more than any granting agency, the wherewithal for its continued advance. Any retreat from the principle of free access to knowledge seems to be a retreat from the unrestrained pursuit of knowledge. Scientific research is an expression of unrestricted curiositas.

The obligation of researchers to provide published materials must be absolute, tempered only by their overriding responsibilities to society. But without sufficient sanctions, some researchers may be tempted to restrict access to their materials for reasons of self-interest. We applaud the stand taken by other journals in demanding adherence to the principle of free availability and deplore the explicit denial of this principle by Nature. Whether the responsibility of Gusella to the patients of Watt et al. outweighs the right of Watt et al. to the probes discovered by Gusella is arguable. But the denial of the existence of the right of Watt et al. to the material is unjustifiable.

Reflecting on the idea of science and the role of curiosity in its history we must agree that "mere curiosity is indeed a sufficient basis for a request".

Miles Brennan

UTE HOCHGESCHWENDER Max-Plank-Institut für Immunbiologie, Postfach 1169, D-7800 Freiburg, FRG

1. Maddox, J. Nature 320, 11 (1986)

. Watt, D.C., Lindenbaum, R.H., Jonasson, J.A. \& Edwards, J.H.; Gusella, J.F. Nature 320, 21-22 (1986)

\section{Paranormal theories}

SIR-David Marks' Commentary on the paranormal (Nature 320, 119; 1986) portrays a marriage between the methods of scientific discourse and political debate. More disinterested observers might still regard the paranormal controversy as a valid exchange of ideas and refrain from attempts to end the discussion by attributing an arbitrary quality of decisiveness to their own work.

Experiments dealing with complex phenomena require the control of multiple variables and it is not unusual for such work to be vulnerable to criticism. As the burden of proof lies in the positive demonstration of paranormal phenomena, it is unlikely that this question will be easily resolved and we must then decide how much "lack of evidence" suffices to prove the non-existence of the alleged phenomena.

In the final analysis, however, the study of such questions may emphasize our humanity more than our objectivity, despite our wish to be impartial. To quote the author: "Beliefs... have an active life of their own and fight tenaciously for their survival. They tell us what to read, what to think, who to trust..." While this statement is certainly true of paranormal investigators, it is also true of others, including Dr Marks, ourselves and perhaps the alleged St Thomas. Dennis Young

85 Woburn Street,

Lexington, Massachusetts 02173, USA 